\title{
Characterization of Self-Assembled Thiols Monolayers on Gold Surface by Electrochemical Impedance Spectroscopy
}

\author{
Renata K. Mendes ${ }^{a}$, Renato S. Freire ${ }^{b}$, Carla P. Fonseca ${ }^{c}$, Silmara Neves ${ }^{c}$ and Lauro T. Kubota ${ }^{*, a}$ \\ ${ }^{a}$ Instituto de Química, Universidade Estadual de Campinas, CP 6154, 13083-970 Campinas - SP, Brazil \\ ${ }^{b}$ Instituto de Química, Universidade de São Paulo, CP 26077, 05513-970, São Paulo - SP, Brazil \\ ${ }^{c}$ LCAM - Centro de Ciências Exatas e Tecnológicas, Universidade São Francisco, 13251-900 Itatiba - SP, Brazil
}

Tióis de cadeias carbônicas com tamanhos diferentes e contendo grupo terminal COOH foram usados para formar monocamadas auto-organizadas sobre a superfície de eletrodos de ouro. A transferência de elétrons do par $\mathrm{Fe}(\mathrm{CN})_{6}^{3-/ 4-}$ para o eletrodo foi estudada em diferentes $\mathrm{pH}$ usandose as técnicas de voltametria cíclica (CV) e de espectroscopia de impedância eletroquímica (EIS). Mudanças no pH da solução resultaram em variações na carga do grupo terminal das monocamadas auto-organizadas e, conseqüentemente, em alterações na interação eletrostática da SAM com as espécies eletroativas em solução.

Thiols with different alkyl chain length and containing $\mathrm{COOH}$ terminal group were self-assembled on gold electrodes. The electron transfer of $\mathrm{Fe}(\mathrm{CN})_{6}^{3-4-}$ couple to the electrode was studied at different $\mathrm{pH}$ by means cyclic voltammetry (CV) and electrochemical impedance spectroscopy (EIS). Changes in solution $\mathrm{pH}$ resulted in the charge variation of the self-assembled monolayer (SAM) terminal group and, consequently, the electrostatic interaction of SAM with the electroactive species in the solution.

Keywords: self-assembled monolayer, cyclic voltammetry, electrochemical impedance spectroscopy, gold electrodes, surface modification

\section{Introduction}

Self-assembled monolayers (SAMs) have attracted much attention in nowadays because their structures and chemical properties make them interesting systems for analytical purposes. ${ }^{1}$ Self-assemblies of organic molecules have been most extensively studied due to their stability, well packed structure, versatility, facility of preparation and the possibility of introducing different chemical functionalities with high level of order on molecular dimension. ${ }^{2}$ One of the most widely used system in the molecular self-assembled method is the chemisorption of sulfur derivatives (i.e. thiols, disulfides) on gold surfaces, ${ }^{3-5}$ due the thermodynamically favorable formation of the bounding gold-thiol. The stability of the bound over a wide range of applied potential makes this system suitable for electrochemical purposes. ${ }^{6}$ The formation of a monolayer on gold is strongly dependent on several factors such as surface cleanness, substrate structure, kind of

*e-mail: kubota@iqm.unicamp.br adsorbate, nature of the adsorbate solvent, temperature, time of the monolayer preparation, concentration and, mainly, the chain length of the thiol used. ${ }^{7}$ In that way, the determination of the influence of the chain length in the properties of the SAMs have been objective of intense researches, because the chain is important in the characteristics of the packing density, intermolecular environment, geometry of the monomolecular assemblies ${ }^{8}$ and the kinetics of adsorption. ${ }^{9}$ However, most of these properties is just studied for alkanes ${ }^{2,10-12}$ and only few reports have described the characterization of the alkanethiols with carboxylic group in the opposite extremity to the sulfur. The alkanethiols terminated with functional groups, especially $\mathrm{COOH}$, are very important for many applications due to the specific functions of the terminal groups, they can be used in the surface properties control and to immobilize different molecules on the monolayer. Besides, thiols functionalities are easier to react than alkanes and, depending on the solution $\mathrm{pH}$, the monolayer can be negatively or positively charged and it could promote electrostatic interactions between the analyte or impurities 
and the SAM. In this way, SAM with carboxylic group can be used as an anchor layer to fabricate sensing electrodes, which can improve the stability and selectivity of sensing films. ${ }^{13,14}$ Among the few studies involving SAM with $\mathrm{COOH}$ terminal group it was not found in the literature any work that uses the electrochemical impedance spectroscopy (EIS) to evaluate the variation of some properties of this monolayer type at different $\mathrm{pH}$ in relation to the carbonic chains length. However there are some works that use other methodologies and obtain interesting results such as the study accomplished by Brevnov et al. ${ }^{15}$ that used $\mathrm{HS}\left(\mathrm{CH}_{2}\right)_{\mathrm{n}} \mathrm{COOH}$, with $\mathrm{n}=5,7$ and 10 to examine the kinetics of electron transfer between SAM and ruthenium complexes. Dijksma et al. ${ }^{16}$ studied the change in characteristics of SAMs of thioctic acid (TA) and 11-mercaptoundecanoic acid (MUA) with time in buffered hexacyanoferrate (II/III) solutions and with subsequently expositing the solution to the light. Chah et al. ${ }^{17}$ investigated SAMs of 3-mercaptopropionic acid (MPA) on gold substrates using surface plasmon resonance (SPR) for determining the rate constant for the formation de MPA SAM in water and the change of refractive index as a function of MPA ionization and reprotonation, depending on the $\mathrm{pH}$. Molinero and $\mathrm{Calvo}^{18}$ have reported the change in the electron transfer between $\mathrm{Fe}(\mathrm{CN})_{6}{ }^{3-}$ and SAMs in different solution $\mathrm{pH}$ due to the different charge of the terminal group $\left(\mathrm{COO}^{-}\right.$and $\left.\mathrm{NH}_{3}^{+}\right)$, using cyclic voltammetry.

Among the techniques used for the monolayers characterization, the use of electrochemical impedance spectroscopy have attracted much interest due to it provides some advantages such as the possibility to evaluate and to understand the structure of a thin monolayer, the dielectric constant and the apparent constant of electron transfer rate of the redox probes in solution, ${ }^{19}$ using the effect of the solution resistance, the charge of double-layer and related current the diffusion or the processes occurring in the SAMs.

The electron transfer between $\mathrm{Fe}(\mathrm{CN})_{6}{ }^{3-}$ and selfassembled monolayer of several alkanethiols, with carboxylic group in the end, on a polycrystalline gold surface was investigated using cyclic voltammetry (CV) and electrochemical impedance spectroscopy (EIS) in the present work. The effect of the solution $\mathrm{pH}$ and the chain length on the electrochemical behavior of the hexacyanoferrate (II/III) couple, are also discussed.

\section{Experimental}

\section{Chemicals}

Mercaptoacetic acid (MAA) and mercaptopropionic acid (MPA) were obtained from Sigma (USA).
Mercaptoundecanoic acid (MUA) and mercaptobenzoic acid (MBA) were purchased from Aldrich (USA). $\mathrm{K}_{3}\left[\left(\mathrm{Fe}(\mathrm{CN})_{6}\right]\right.$ was acquired from J.T.Baker (USA). All used chemicals were of analytical grade and used as received. Solutions were prepared with deionized water (> $18 \mathrm{M} \Omega$ cm, Milli-Q, Millipore Inc., USA).

\section{Apparatus}

The voltammetric and impedance measurements were performed using a potentiostat PGSTAT 30 model from AUTOLAB (Eco Chemie, Netherlands), interfaced with a personal computer. The geometrical area of the gold working electrode (Metrohm 6.1204.020, Switzerland) was $0.07 \mathrm{~cm}^{2}$. All electrochemical experiments were carried out in a conventional three electrode cell at room temperature, a saturated calomel electrode (SCE) and a Pt wire were used as reference and counter electrodes, respectively.

\section{Monolayer preparation}

Before SAM preparation, a cleaning process of the electrode surface was performed. First the electrode surface was polished with alumina slurry $0.3 \mu \mathrm{m}$ (Metrohm, Switzerland), after the polishing treatment, the electrode was washed with large amount of deionized water and then sonicated in pure ethanol for $5 \mathrm{~min}$. In a second step, the electrode was cleaned by its immersion into a "piranha" solution (3:7 mixture of $30 \% \mathrm{H}_{2} \mathrm{O}_{2}$ and concentrated $\mathrm{H}_{2} \mathrm{SO}_{4}$ ) for $10 \mathrm{~min}$ and then it was rinsed in deionized water. Finally, the gold electrode was electrochemically cleaned in 0.5 mol L-1 $\mathrm{H}_{2} \mathrm{SO}_{4}$ solution, cycling the potential between 0.1 and $1.4 \mathrm{~V}$ (SCE) during 25 scans. The final cyclic voltammogram was compared to those reported by Finklea et $a l .{ }^{4}$ in order to warranty that a clean gold surface was being used in each time. Then, the electrode was transferred immediately to $10 \mathrm{mmol} \mathrm{L}^{-1}$ solution of the respective alkanethiol in ethanol. To prepare a well-assembled thiol monolayer, the gold electrode was immersed into the thiol solution during $18 \mathrm{~h}$. The modified electrode was further rinsed with ethanol to remove physically adsorbed molecules. The electrochemical measurements were taken immediately before and after coating each electrode.

\section{Electrochemical measurements}

The voltammetric measurements of the gold modified electrodes were recorded using a $5 \mathrm{mmol} \mathrm{L}^{-1} \mathrm{Fe}(\mathrm{CN})_{6}^{3-}$ solution in $0.1 \mathrm{~mol} \mathrm{~L}^{-1} \mathrm{KCl}$ at $\mathrm{pH} 4.0$ and 8.0 cycling the potential between -0.4 and $0.3 \mathrm{~V}$ vs. SCE (scan rate: 100 $\mathrm{mV} \mathrm{s}^{-1}$ ). For impedance studies, it was applied sine wave 
with $10 \mathrm{mV}$ of amplitude to the electrode over the formal potential of the redox couple $(0.2 \mathrm{~V})$. Impedance spectra were collected in the frequency range between $10^{5}$ and $10^{-2} \mathrm{~Hz}$. Before each frequency sweep, the electrode was prepolarized at OCP for about $1 \mathrm{~h}$. Electrochemical impedance spectra were fitted using an Equivalent Circuit contained on the FRA software (AUTOLAB, Eco Chemie, Netherlands) and the resistance of charge transfer $\left(\mathrm{R}_{\mathrm{ct}}\right)$ values were determined for $\mathrm{Fe}(\mathrm{CN})_{6}^{3-14-}$ from the experimental data at different $\mathrm{pH}$ (4.0 and 8.0).

\section{Results and Discussion}

Cyclic voltammetry (CV) experiments of the gold electrodes with different alkanethiol monolayers with $\mathrm{COOH}$ terminal group were performed in order to determine the effect of solution $\mathrm{pH}$ on the rate of electron transfer process that take place at electrodes changing the surface charge with $\mathrm{pH}$.

The CVs obtained for Au-SAM in $\mathrm{Fe}(\mathrm{CN})_{6}^{3-14}$ solution at different $\mathrm{pH}$ are shown in Figure 1. As can be seen, the peaks current increase greatly and the electron transfer becomes more reversible at lower solution $\mathrm{pH}$, where full protonation of the $\mathrm{COOH}$ terminal group is expected. At low $\mathrm{pH}$, the $\mathrm{CVs}$ of $\mathrm{Fe}(\mathrm{CN})_{6}^{3-14-}$ obtained using thiol modified electrodes were not noticeably different from those observed at bare gold electrode, except for mercaptoundecanoic acid (MUA), in which a complete passivation of the electrode surface can be observed, independently on the solution $\mathrm{pH}$. It is well know that long alkanethiols can form dense, well-ordered and stable monolayer on gold, while for short chain thiols are the opposite. Thus, this behavior can be explained by this property. The short-chain thiol monolayer on gold is too thin to effectively block electron transfer on a gold surface, on the other hand and the MUA SAM $\left(\mathrm{SH}\left(\mathrm{CH}_{2}\right)_{10} \mathrm{COOH}\right)$ cover the electrode surface and block electron transfer, independently of the solution $\mathrm{pH}$.

At higher $\mathrm{pH}$, the terminal groups of the monolayer are deprotonated and becomes negatively charged. As the hexacyanoferrate is negatively charged, it should have a repulsive force between the SAM modified electrode surface and the electroactive species in solution, making difficult the electron transfer. This can be clearly observed by the shape of the voltammograms at $\mathrm{pH} 8$ (Figure 1). For the MAA, which have only one $\mathrm{CH}_{2}$ group, the influence of the solution $\mathrm{pH}$ on the voltammetric response is small because it almost possesses the same properties of the bare gold and it is not able to block the electron transfer.

In order to get more kinetic information, the electrochemical impedance spectroscopy was employed.

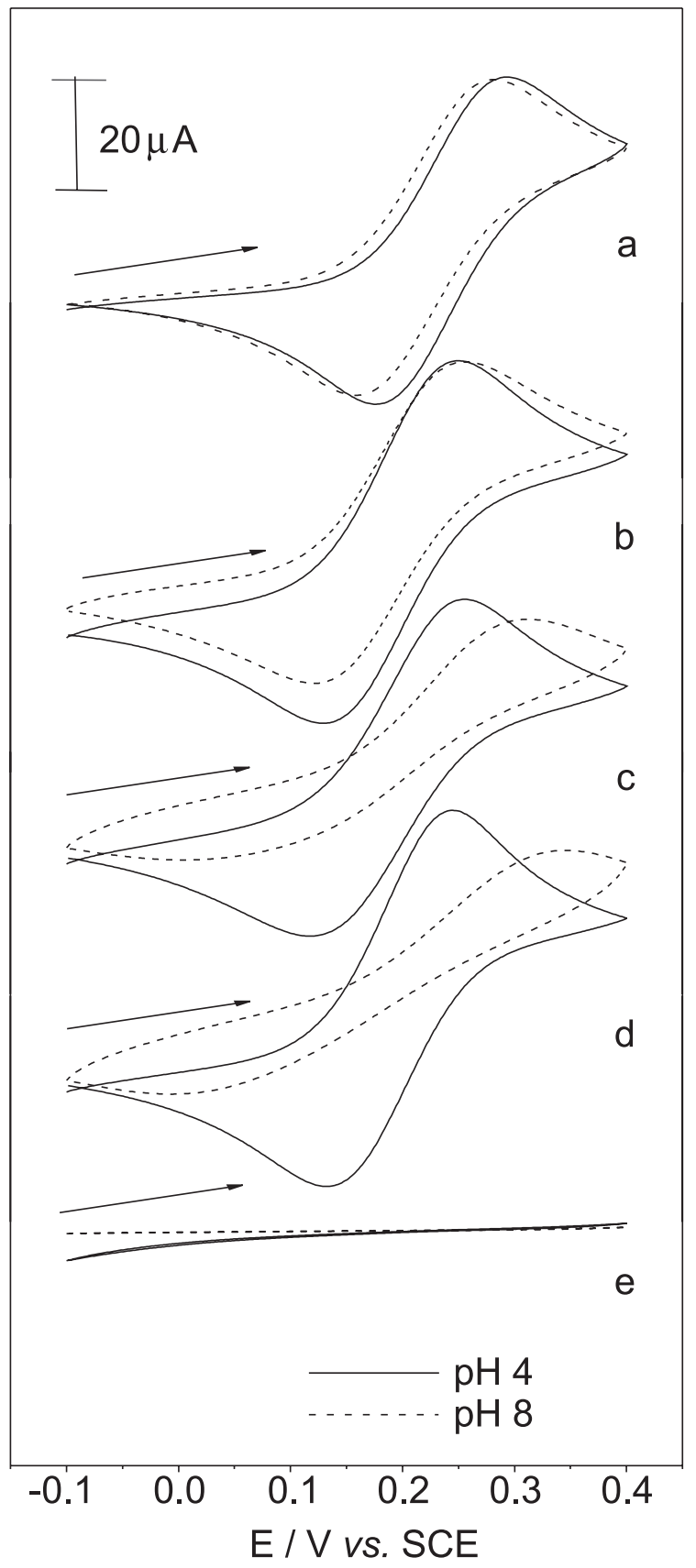

Figure 1. Cyclic voltammograms of $5 \mathrm{mmol} \mathrm{L}^{-1} \mathrm{Fe}(\mathrm{CN})^{3-}$ in $0.1 \mathrm{~mol}$ $\mathrm{L}^{-1} \mathrm{KCl}$ solution at $\mathrm{pH} 4$ and 8 (a) bare gold, (b) mercaptoacetic acid (MAA), (c) mercaptopropanoic acid (MPA), (d) mercaptobenzoic acid (MBA) and (e) mercaptoundecanoic acid (MUA). Scan rate: $100 \mathrm{mV} \mathrm{s}^{-1}$.

The ac impedance method is based upon a measurement of the response of the electrochemical cell to a smallamplitude alternating potential and monitoring phase shift of the current response. The procedure is performed over a range of frequencies..$^{20}$ The response is often shown in the complex-impedance presentation, and the result can be interpreted in terms of an equivalent electrical circuit. However, difficulties in processing data using electrical 
analogs often arise because the non-linearity in the proposed equivalent circuit. ${ }^{21}$

EIS of thiol modified gold surfaces was investigated at a constant concentration of redox species $\mathrm{Fe}(\mathrm{CN})_{6}^{3-1 / 4}$ (5 $\mathrm{mmol} \mathrm{L}^{-1}$ ) and variable $\mathrm{pH}$. Typical Nyquist diagrams are shown in Figure 2 and 3 respectively, for $\mathrm{pH} 4$ and 8. The impedance-plane plots of Figures 2 and 3 are characterized by two distinct regions: $(i)$ a semicircle in higher frequency related to charge transfer process, which was electrically described by a resistance in parallel with a capacitor related to the charge-transfer and electrode/SAM double-layer, respectively. It contains contributions from the bathing electrolyte, too; (ii) A $45^{\circ}$ line in the complex-plane impedance plot defining a Warburg region of semi-infinite diffusion of species in the modified electrode.

The circuit model used in this study was a modified Randles circuit: $R_{s}\left(Q\left[R_{c t} W\right]\right)$ where $R_{s}$ is the resistance of the solution, $R_{c t}$ is the resistance of the charge-transfer to a species moving through the film, $\mathrm{W}$ is the Warburg impedance and $\mathrm{Q}$ is the constant phase element, $\mathrm{CPE}$, and the impedance $(\mathrm{Z})$ is then given by:

$\mathrm{Z}_{\mathrm{CPE}}=1 / \mathrm{Q}(\mathrm{j} \omega)^{\varphi}$

where $\mathrm{j}=(-1)^{1 / 2}, \omega=2 \pi f$ being $f$ the frequency of the applied $a c$ potential and $\varphi$ is fractional and its experimental value is between 0.5 (for an ideally porous electrode) and 1 (for a perfect smooth electrode).

The CPE is a power law-dependent interfacial capacity and take accounts the topological imperfections of the gold surface caused by the different crystal facets and the

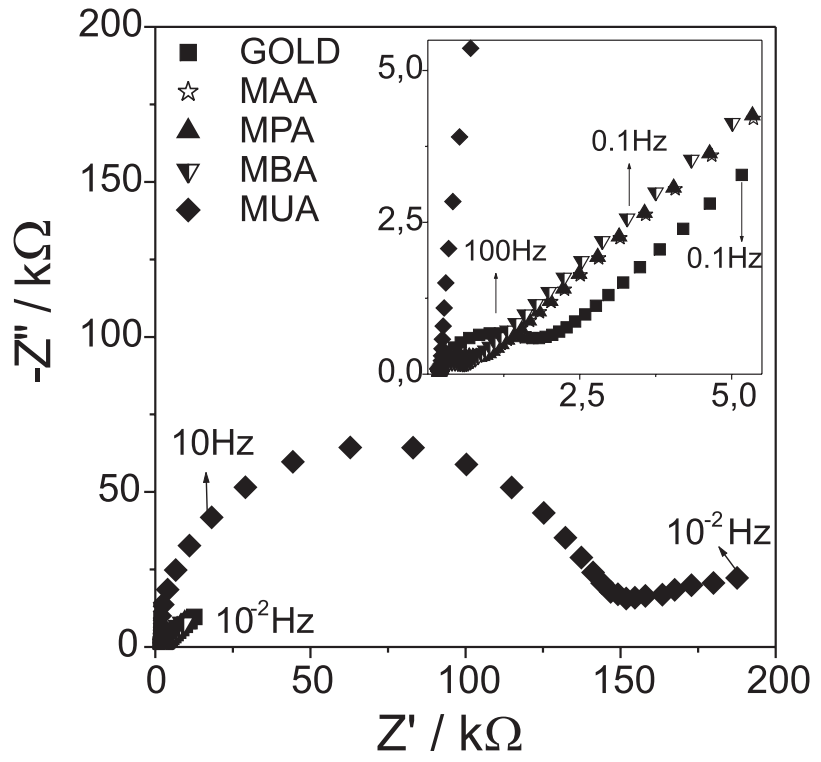

Figure 2. Nyquist plots for $5 \mathrm{mmol} \mathrm{L}^{-1} \mathrm{Fe}(\mathrm{CN})_{6}^{3-}$ in $0.1 \mathrm{~mol} \mathrm{~L}^{-1} \mathrm{KCl}$ solution using Au-SAM at $\mathrm{pH} 4 . f=0.01$ to $10 \mathrm{kHz}$.

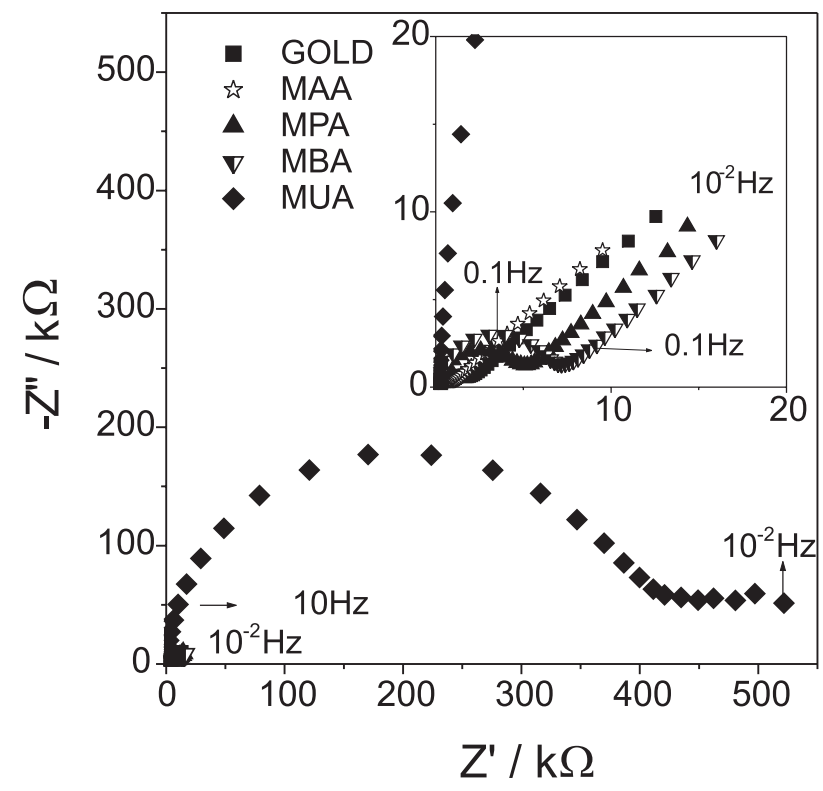

Figure 3. Nyquist plots for $5 \mathrm{mmol} \mathrm{L}^{-1} \mathrm{Fe}(\mathrm{CN})_{6}{ }^{3-}$ in $0.1 \mathrm{~mol} \mathrm{~L}^{-1} \mathrm{KCl}$ solution using Au-SAM at $\mathrm{pH}$ 8. $f=0.01$ to $10 \mathrm{kHz}$.

surface roughness of the electrode. If $\varphi=1$, the $\mathrm{CPE}$ is an ideal capacitor, ${ }^{21} \mathrm{Q}=\mathrm{C}_{\mathrm{dl}}$, double-layer capacitance. The $\mathrm{CPE}$ corrects for the flattened semicircle, which originates from apparent noncapacitive properties of the surface. The exact physical meaning is still unknown. ${ }^{22}$ The CPE was used instead of the ideal capacitor in every fit in order to improve the final fit and minimize errors. A small deviation from $1.0(\varphi>0.85)$, as observed here, suggests that the gold substrates are adequately smooth for these studies. ${ }^{23}$

The impedance-plane plots of Figures 2 and 3 are characterized by depressed semi-circles with low frequency Warburg lines, similar to those reported for Molinero and $\mathrm{Calvo}^{18}$ that studied the electron transfer of $\mathrm{Fe}(\mathrm{CN})_{6}^{3-14-}$ at gold electrodes modified with thioacetate.

We can verify in these diagrams that $\mathrm{R}_{\mathrm{ct}}$ increase with the number of $\mathrm{CH}_{2}$ groups in the carbonic chain, because there is a tendency to a larger passivation of the surface in longer chains. In Figure 3 (pH 8), it can be observed that $\mathrm{R}_{\mathrm{ct}}$ is larger than that obtained at $\mathrm{pH} 4$, because there is a repulsive force between the electroactive species and surface, similar to the results obtained in Figure 1, using $\mathrm{CV}$. Figure 4 gives an idea of the difference in the resistance in both $\mathrm{pHs}$, and the difference when compared with bare gold. If the molecule probes used in the study it had positive charge, the $\mathrm{R}_{\mathrm{ct}}$ it would be larger in higher $\mathrm{pH}$, in the which SAM is deprotonated and it would happen an attraction between the electrode surface and the analite. In the case of this study, the effect is inverse because the molecule probe has negative charge $\left(\mathrm{Fe}(\mathrm{CN})_{6}{ }^{3}\right)$ and $\mathrm{R}_{\mathrm{ct}}$ is larger in $\mathrm{pH} 8$, where it happens deprotonation of SAM 


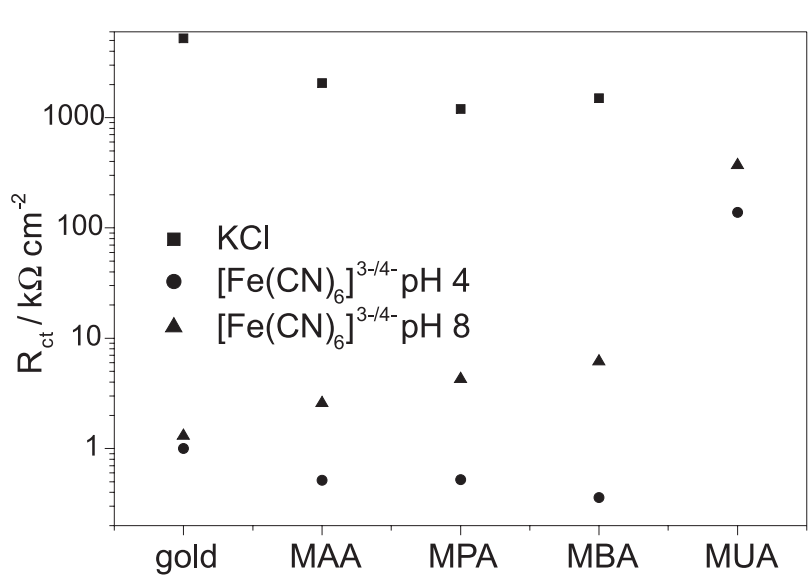

Figure 4. $\mathrm{R}_{\mathrm{ct}}$ vs. Au-SAM plot for $0.1 \mathrm{~mol} \mathrm{~L}^{-1} \mathrm{KCl}$ solution and 5 mmol L-1 $\mathrm{Fe}(\mathrm{CN})_{6}^{3-}$ in $0.1 \mathrm{~mol} \mathrm{~L}^{-1} \mathrm{KCl}$ solution at $\mathrm{pH} 4$ and 8 .

and, consequently, repulse among charges. The values of $\mathrm{R}_{\mathrm{ct}}$ for MBA can be explained by the presence of the aromatic chain, which should be favoring in some way the electron transfer between the SAM and the electroactive species. On Table 1 are listed the values obtained for $\mathrm{R}_{\mathrm{ct}}$ and $\mathrm{C}$ (capacitance) with different SAMs. The values of $\mathrm{C}$ are opposed to the of the resistance and decreases as the carbonic chain increase. The simplest view of the thiolcovered electrode is considering an ideal capacitor with a plate distance depending on the number of carbon atoms (n) in the alkyl-chain. When $\mathrm{n}$ is increased, the hydrophobicity increases and the capacitance per element volume decreases. Swietlow et al. ${ }^{20}$ also verified that the capacitance decrease as increase the carbonic chain in the monolayers, independently of the terminal group in SAM.

The electrode coverage $(\theta)$ is a key factor that can be used to estimate the surface state of the electrode and related

Table 1. Parameters obtained for different SAMs on a gold electrode from impedance plots in $5.0 \mathrm{mmol} \mathrm{L}^{-1} \mathrm{Fe}(\mathrm{CN})_{6}^{3-/ 4-}$ solution

\begin{tabular}{lcccc}
\hline & \multicolumn{2}{c}{$\mathrm{R}_{\mathrm{ct}} / \mathrm{k} \Omega$} & \multicolumn{2}{c}{$\mathrm{C} / \mu \mathrm{F} \mathrm{cm}^{-2}$} \\
Electrode & $\mathrm{pH} 4$ & $\mathrm{pH} 8$ & $\mathrm{pH} 4$ & $\mathrm{pH} 8$ \\
\hline BARE & 0.00676 & 0.00672 & 0.86 & 1.02 \\
$\mathrm{Au} /$ MAA & 0.556 & 2.53 & 1.59 & 1.50 \\
$\mathrm{Au} / \mathrm{MPA}$ & 0.559 & 4.20 & 1.31 & 1.20 \\
$\mathrm{Au} /$ MBA & 0.379 & 6.21 & 0.762 & 0.941 \\
$\mathrm{Au} /$ MUA & 136 & 375 & 0.298 & 0.290 \\
\hline
\end{tabular}

to the resistance of the charge transfer. It is reasonable to assume that highly compact and hydrofobic monolayers are practically insulating under usual electrochemical conditions, except in the existence of pinholes due to structural imperfections. Pinholes are a kind of defect in a thiol monolayer and they allow molecules and ions, from the electrolyte, reach the electrode surface. Assuming that all the current is passed by pinholes on the electrode, the electrode coverage can be calculated by: ${ }^{24}$

$(1-\theta)=\mathrm{R}_{\mathrm{ct}}^{\circ} / \mathrm{R}_{\mathrm{ct}}$

where $\mathrm{R}_{\mathrm{ct}}{ }^{\circ}$ is the charge-transfer resistance at bare gold and $\mathrm{R}_{\mathrm{ct}}$ is the charge-transfer resistance at the monolayercovered electrode under the same condition. $\mathrm{R}_{\mathrm{ct}}$ was obtained in different $\mathrm{pHs}$, it was possible to have the covering fraction for both $\mathrm{pH}$. The results are given in Table 2. As it can be observed, the values of $R_{c t}$ are used for the calculation of the electrode coverage and, in that way, as the resistance of the SAM is larger, in this case, in higher $\mathrm{pH} 8$, the coverage of the monolayer should be larger. This makes sense, once in lower $\mathrm{pH}$ there is a larger amount of pinholes, allowing more molecules or ions to reach the electrode surface, what decreases the resistance of charge transfer of the monolayer and, consequently, the electrode coverage.

Assuming a parallel combination of two parallel-plate capacitors, the first is assigned to the double-layer capacitance at the pinholes, and the second is assigned to the build up of charge across the monolayer, itself. The Z-plot can be used to evaluate ${ }^{24}$ the total capacitance, C:

$\mathrm{C}=\mathrm{C}_{\mathrm{dl}}{ }^{\circ}(1-\theta)+\mathrm{C}_{\mathrm{m}}{ }^{\circ} \theta$,

where $\mathrm{C}_{\mathrm{dl}}{ }^{\circ}$ is the capacitance obtained for bare gold, $\mathrm{C}$ is the capacitance for SAM-modified gold that can be evaluated from the Z-plot and $\mathrm{C}_{\mathrm{m}}{ }^{\circ}$ is the capacitance of the defect-free monolayer, assuming $100 \%$ coverage. This $\mathrm{C}_{\mathrm{m}}{ }^{\circ}$ can be used to calculate the dielectric constant $\left(\varepsilon_{\mathrm{m}}\right)$ of the monolayer, ${ }^{19}$ as show the equation below. The results are given in Table 2.

$\varepsilon_{\mathrm{m}}=\mathrm{C}_{\mathrm{m}}^{\circ} \mathrm{d} / \varepsilon_{0}$

Table 2. Parameters obtained for different $\mathrm{SAMs}$ on a gold electrode from impedance plots in $5.0 \mathrm{mmol} \mathrm{L}^{-1} \mathrm{Fe}(\mathrm{CN})_{6}^{3-14-}$ solution

\begin{tabular}{lcccccccc}
\hline & \multicolumn{2}{c}{$\theta / \%$} & \multicolumn{2}{c}{$\mathrm{C}_{\mathrm{m}} / \mu \mathrm{F} \mathrm{cm}^{-2}$} & \multicolumn{2}{c}{$\varepsilon_{\mathrm{m}}$} & \multicolumn{2}{c}{$\mathrm{k}_{\text {app }} / \mathrm{cm} \mathrm{s}^{-1}$} \\
\hline SAM & $\mathrm{pH} 4$ & $\mathrm{pH} 8$ & $\mathrm{pH} 4$ & $\mathrm{pH} 8$ & $\mathrm{pH} \mathrm{4}$ & $\mathrm{pH} 8$ & $\mathrm{pH} 4$ & $\mathrm{pH} 8$ \\
MAA & 98.78 & 99.73 & 1.602 & 1.462 & 0.815 & 0.743 & $9.5710^{-5}$ & $2.1010^{-5}$ \\
MPA & 98.79 & 99.84 & 1.313 & 1.198 & 0.742 & 0.677 & $9.5210^{-5}$ & $1.2710^{-5}$ \\
MBA & 98.22 & 99.89 & 0.760 & 0.940 & 0.670 & 0.830 & $1.4010^{-4} 8.5710^{-6}$ \\
MUA & 99.98 & 99.99 & 0.297 & 0.289 & 0.638 & 0.637 & $3.9110^{-7} 1.4110^{-7}$ \\
\hline
\end{tabular}


where $\mathrm{d}$ is the monolayer thickness (MAA $\sim 0.45 \mathrm{~nm}$; MPA $=0.50 \mathrm{~nm},{ }^{16}$ MBA $\sim 0.78 \mathrm{~nm}^{17}$ and MUA $=1.90 \mathrm{~nm}^{25}$ ), and $\varepsilon_{0}$ is the permeability in the free space $\left(8.8510^{-12} \mathrm{C}^{2} \mathrm{~N}^{-1}\right.$ $\mathrm{m}^{-2}$ ). The results are given in Table 2 .

The charge-transfer rate of the $\mathrm{Fe}(\mathrm{CN})_{6}^{3-/ 4-}$ couple can be calculated from the Nyquist diagram for the gold electrode modified with SAM. Assuming a transfer coefficient (a) of 0.5 , for the $1^{\text {st }}$-order reaction with $\mathrm{c}_{\mathrm{o}}=\mathrm{c}_{\mathrm{r}}=$ $c\left(c_{o}\right.$ and $c_{r}$ equal the concentration of oxidized and reduced species at the surface, respectively): $:^{26}$

$\mathrm{k}_{\mathrm{app}}=\mathrm{RT} / \mathrm{F}^{2} \mathrm{R}_{\mathrm{ct}} \mathrm{c}$

where $\mathrm{k}_{\text {app }}$ is the apparent rate constant at the SAMmodified electrode, $\mathrm{R}$ is the gas constant, $\mathrm{T}$ is temperature, $\mathrm{F}$ is the Faraday constant, the $\mathrm{R}_{\mathrm{ct}}$ is the charge-transfer resistance at the monolayer-covered electrode and $\mathrm{c}$ is the concentration of the redox couple. The results are given in Table 2 .

Observing the data listed on Table 2, it is verified that 18 hours of immersion of the electrode in the thiol solution is enough to form a monolayer with almost $100 \%$ of covering, reducing possible defects in the surface. The decrease of the defects can be confirmed checking the low values obtained for $\mathrm{C}_{\mathrm{m}}{ }^{\circ}$, which was due to small amount of defects in the formed SAM. Besides, these values tend to decrease as increasing the carbonic chain of the thiol, because thiols with long chains form SAMs closely packed, reducing the pinholes presence. The same can be observed at lower $\mathrm{pH}$. In these conditions the monolayer is protonated and it doesn't happen interchain repulsive force, because SAM possesses neutral load, avoiding the pinholes formation. When the monolayer is deprotonated $(\mathrm{pH} 8)$, it can have repulsive force among the carbonic chains, which they are negatively charged, promoting defects in SAM. Larger values of $\mathrm{C}_{\mathrm{m}}{ }^{\circ}\left(12.56 \mu \mathrm{Fcm}^{-2}\right)$ was found by Wang $e t$ $a l .{ }^{19}$ for SAM formed by 2 hours, indicating the existence of defects in the gold surface when it is prepared in short periods of time. Due to the low values obtained for $\mathrm{C}_{\mathrm{m}}{ }^{\circ}$ in this study, the dielectric constant of those SAMs presented low values, because the calculation for obtaining the results is directly related to the $\mathrm{C}_{\mathrm{m}}{ }^{\circ}$ values.

The apparent rate constant $\left(\mathrm{k}_{\mathrm{app}}\right)$ also tends to decrease with the increase of the carbonic chain, because there is an increase in the blocking of the electron transfer for longer chains. This behavior is not observed for the mercaptobenzoic acid (MBA), probably because the aromatic chain should have an important effect to favor the rate of electron transfer. Due to the repulsive force between the redox couple and surface, in higher $\mathrm{pH}$, the $\mathrm{k}_{\text {app }}$ is smaller because the electron transfer is more difficult.
Protsailo and Fawcett ${ }^{21}$ obtained similar results, observing a decrease of $k_{\text {app }}$ for longer alkyl chain of SAMs formed by alkanes.

\section{Conclusion}

Using the monolayers formed on gold by four different thiols (MAA, MPA, MBA and MUA) it was illustrated that the variation of the charge-transfer resistance $\left(\mathrm{R}_{\mathrm{c}}\right)$ and the apparent rate constant $\left(\mathrm{k}_{\text {app }}\right)$ with the alkyl chain length and solution $\mathrm{pH}$. Changes in solution $\mathrm{pH}$ resulted in a charge variation of the terminal group of the self-assembled monolayer (SAM) and, consequently, alterations in the electrostatic interaction between SAM and electroactive species in solution. $\mathrm{R}_{\mathrm{ct}}$ increased as the alkyl chain, because thiols with long chains form SAMs closely packed. In higher $\mathrm{pH}, \mathrm{R}_{\mathrm{ct}}$ is larger due to the repulsive force between the $\mathrm{Fe}(\mathrm{CN})_{6}^{3-14}$-redox couple and the monolayer. For $\mathrm{k}_{\text {app }}$ the effect is inverse and it decreases as the increase of the alkyl chain, because long chains make the electrons transfer more difficult. It is also possible to observe that aromatic compounds like mercaptobenzoic acid proportionate easier electron transfer, probably due to the resonance property.

\section{Acknowledgements}

Financial support from FAPESP and CAPES.

\section{References}

1. Ulman, A.; Chem. Rev. 1996, 96, 1533.

2. Xing, Y.F.; O'Shea, S.J.; Li, S.F.Y.; J. Electroanal. Chem. 2003, $542,7$.

3. Finklea, H.O.; Avery, S.; Lynch, M.; Langmuir 1987, 3, 409.

4. Sellers, H.; Ulman, A.; Shnidman, Y.; Eilers, J.E.; J. Am. Chem. Soc. 1993, 115, 9389.

5. Bain, C.D.; Evall, J.; Whitesides, G.M.; J. Am. Chem. Soc. 1989, 111, 7155 .

6. Rowe, G.K.; Creager, S.E.; Langmuir 1991, 7, 2307.

7. Yang, Z.; Gonzalez-Cortes, A.; Jourquin, G.; Viré, J.; Kauffmann, J.; Delplancke, J.; Biosens. Bioelectron. 1995, 10, 789 .

8. Porter, M.D.; Bright, T.B.; Allara, D.L.; Chidsey, C.E.D.; J. Am. Chem. Soc. 1987, 109, 3559.

9. Subramanian, R.; Lakshminarayanan, V.; Electrochim. Acta 2000, 45, 4501.

10. Krysinski, P.; Brzostowska-Smolska, M.; J. Electroanal. Chem. 1997, 424, 61.

11. Finklea, H.O.; Snider, D.A.; Fedyk, J.; Langmuir 1990, 6, 371. 
12. Peterlinz, K.A.; Georgiadis, R.; Langmuir 1996, 12, 4731.

13. Freire, R.S.; Kubota, L.T.; Analyst 2002, 127, 1502.

14. Freire, R.S.; Kubota, L.K.; Electrochim. Acta 2004, 49, 3795.

15. Brevnov, D.A.; Finklea, H.O.; Ryswyk, H.V.; J. Electroanal. Chem. 2001, 500, 100.

16. Dijksma, M.; Boukamp, B.A,; Kamp, B.; Van Bennekom, W.P.; Langmuir 2002, 18, 3105.

17. Chah, S.; Yi, J.; Pettit, C.M.; Roy, D.; Fendler, J.H.; Langmuir 2002, 18, 314.

18. Molinero, V.; Calvo, E.J.; J. Electroanal. Chem. 1998, 445, 17.

19. Wang, J.; Zeng, B.; Fang, C.; Zhou, X.; Anal. Sci. 2000, 16, 457.

20. Swietlow, A.; Skoog, M.; Johansson, G.; Electroanalysis 1992 , 4, 921.
21. Protsailo, L.V.; Fawcett, W.R.; Electrochim. Acta 2000, 45, 3497.

22. Dijksma, M.; Kamp, B.; Hoogvliet, J.C.; Van Bennekom, W.P.; Langmuir 2000, 16, 3852.

23. Boubour, E.; Lennox, B.; Langmuir 2000, 16, 4222.

24. Sabatani, E.; Rubinstein, I.; J. Electroanal. Chem. 1987, 219, 365 .

25. Chidsey, C.E.D.; Loiacono, D.N.; Langmuir 1990, 6, 682.

26. Diao, P.; Jiang, D.; Cui, X.; Gu, D.; Tong, R.; Zhog, B.; J. Electroanal. Chem. 1999, 464, 61.

Received: January 30, 2004 Published on the web: October 15, 2004

FAPESP helped in meeting the publication costs of this article. 